International Journal of Advanced Trends in Computer Science and Engineering

Available Online at http://www.warse.org/IJATCSE/static/pdf/file/ijatcse21942020.pdf

https://doi.org/10.30534/ijatcse/2020/21942020

\title{
WOA based Reduced Order Modeling of LTIC Systems
}

\author{
Jay Kumar ${ }^{1}$, Girish Parmar ${ }^{2}$ \\ ${ }^{1}$ Research Scholar, Department of Electronics Engineering, Rajasthan Technical University, Rawatbhata Road, \\ Kota-324010 (Rajasthan), India.jaykumar_1981@yahoo.co.in \\ ${ }^{2}$ Associate Professor,Department of Electronics Engineering, Rajasthan Technical University, Rawatbhata Road, \\ Kota-324010(Rajasthan), India. girish_parmar2002@yahoo.com
}

\begin{abstract}
In this paper, the Whale Optimization Algorithm (WOA) has been employed in reduced order modeling of higher order linear time invariant continuous (LTIC) single-input single-output (SISO) systems. The algorithm has considerable features such as; superior performance, fast convergence, trouble-free implementation and gives numerically stable system. The strength of WOA has been tested on three types of systems having complex roots, repeated poles and also on one of the practical IEEE type 1 (DC) excitation model of $4^{\text {th }}$ order. In the present work, WOA minimizes the Integral Square Error (ISE) as an objective function to obtain all the gain parameters of numerator and denominator's polynomials of low order system (LOS). A comparative study has also been included to compare the proposed technique with some of famous/recent techniques existing in the literature for order reduction on the basis of ISE, IAE, IRE and various transient response parameters. The simulation results have been provided in graphical as well as tabular forms.
\end{abstract}

Key words : Integral Square Error, Integral Absolute Error, Impulse Response Energy, Order Reduction, Stability, Whale Optimization Algorithm.

\section{INTRODUCTION}

For higher order system (HOS), study and design of practical control systems are very tedious. Therefore, there is a necessity to reduce the order of HOS for which some generalization algorithms are required. These algorithms must be implemented in such away that the reduced equivalent LOS must not lose its original HOS's characteristics. Over many years, various techniques for model order reduction have been invented for simplification such as; system simplification techniques based on balanced truncation [1], whale optimization algorithm [2,6], combined techniques like: Eigen Spectrum Analysis (ESA) \& Pade Approximation [3], ESA \& Factor Division [4] and Eigen Permutation \& Improved Pade Approximant (IPA) [7], different evolutionary algorithms like: Particle Swarm Optimization (PSO) [5] and Invasive Weed Optimization (IWO) [15].
Further, numerous techniques carried out by the researchers all around the world are available for MOR such as; design of control systems based on LOS [8], comparative analysis of different techniques [9], mixed method [10], Cuckoo Search optimization [11], Big Bang-Big Crunch (BB-BC) algorithm [12, 14], soft computing techniques [16-17], Modified Cuckoo Search (MCS) algorithm [18], Stochastic Fractal Search (SFS) [20], the Routh Approximation [21], Stability Equation [22], differentiation [23], Response Matching Techniques [24], Pole Clustering [25] methods and many more [34-40].

In present work, Whale Optimization Algorithm (WOA) for order reduction of LTIC systems has been explored by minimizing the ISE as an objective function. WOA is based on humpback behavior of whales. The obtained results are also compared with some various recent techniques available in literature.

\section{STATEMENT OF PROBLEM}

An $n^{\text {th }}$ order SISO-LTI-HOS has been defined by the following transfer function (TF):

$$
G_{n}(s)=\frac{a_{0}+a_{1} s^{2}+a_{2} s^{2}+\ldots \ldots \ldots+a_{n} s^{n-1}}{b_{0}+b_{1} s+b_{2} s^{2}+\ldots \ldots \ldots+b_{n} s^{n}}
$$

Suppose, the reduced $r^{\text {th }}$ order LOS is given as:

$$
R_{r}(s)=\frac{\alpha_{0}+\alpha_{1} s+\alpha_{2} s^{2}+\ldots \ldots \ldots+\alpha_{r} s^{r-1}}{\beta_{0}+\beta_{1} s+\beta_{2} s^{2}+\ldots \ldots \ldots+\beta_{r} s^{r}}
$$

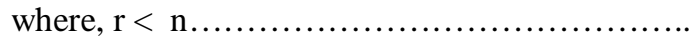

The objective function: ISE is defined as $[12,19,20,22]$ :

$$
I S E=\int_{0}^{\infty}\left[y(t)-y_{r}(t)\right] d t
$$

The other performance indices used in present work are given as $[19,22]$ :

$$
I A E=\int_{0}^{\infty}|e(t)| d t
$$


Jay Kumar et al., International Journal of Advanced Trends in Computer Science and Engineering, 9(4), July - August 2020, 4315 - 4321

$$
I R E=\int_{0}^{\infty} g^{2}(t) d t
$$

where, $g(t)$ is the impulse response of the system.

\section{WHALE OPTIMIZATION ALGORITHM (WOA)}

A set of random solutions initiate the WOA algorithm in which search agents update their positions with each iteration and best solution obtained so far. In this paper, the application of WOA has been explored in the field of model order reduction and the detailed explanation of WOA along with its steps for implementing the algorithm, pseudo codes, flow chart and mathematical modeling can be found in $[2,6]$.

\section{NUMERICAL EXAMPLES AND SIMULATION RESULTS}

Three Simulation Examples have been incorporated for exemplifying the algorithm for the present work.

\subsection{Example-1}

Let us consider a $9^{\text {th }}$ order system with complex roots be defined as $[12,18]$ :

$\mathrm{G}_{9}(s)=\frac{s^{4}+35 s^{3}+291 s^{2}+1093 s+1700}{s^{9}+9 s^{8}+66 s^{7}+294 s^{6}+1029 s^{5}+2541 s^{4}+4684 s^{3}+5856 s^{2}+4620 s+1700}$

After WOA being run 100 times, the reduced $3^{\text {rd }}$ order denominator's and numerator's polynomials of WOA based LOS are obtained as:

$$
\begin{aligned}
& D_{2}(s)=s^{3}+1.6457 s^{2}+2.1714 s+1.0602 \\
& N_{2}(s)=0.001 s^{2}+0.001 s+1.0602
\end{aligned}
$$

Therefore, the $3^{\text {rd }}$ order LOS by proposed technique is:

$$
R_{3}(s)=\frac{0.001 s^{2}+0.001 s+1.0602}{s^{3}+1.6457 s^{2}+2.1714 s+1.0602}
$$

The WOA yields the ISE as $1.632 \times 10^{-2}$ and the reduced model obtained by [18] is given as:

$$
R_{3}(s)=\frac{0.001935 s^{2}+0.005725 s+1.073}{s^{3}+1.681 s^{2}+2.183 s+1.073}
$$

The transfer function of reduced $3^{\text {rd }}$ order model of the same system by stability equation and Big-Bang Big Crunch method [12] is given by:

$$
R_{3}(s)=\frac{0.0789 s^{2}+0.3142 s+0.493}{s^{3}+1.3 s^{2}+1.34 s+0.493}
$$

The convergence of objective function; ISE by WOA is shown in Figure 1.

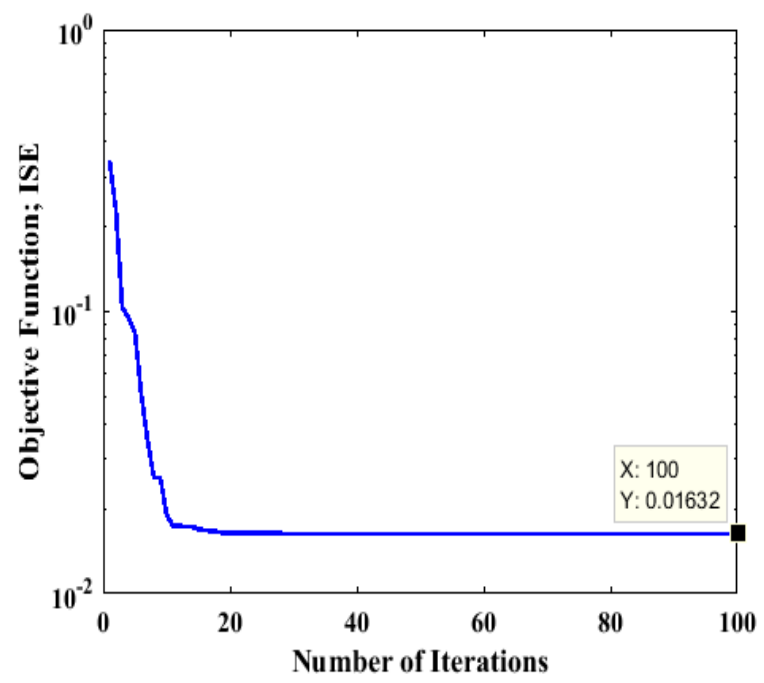

Figure 1: Convergence of objective function for Example-1

The comparison of responses, its parameters and performance indices obtained by the proposed WOA and some recent algorithms for $9^{\text {th }}$ order HOS and $3^{\text {rd }}$ order LOS have been shown in Figures2-3 and Tables1(a)-1(b). It is found that (i) A better match of transient response of LOS obtained by WOA with original HOS has been found.(ii)The parameters of $3^{\text {rd }}$ order LOS obtained by WOA and original $9^{\text {th }}$ order HOS are comparable. (iii)The LOS obtained by WOA exhibits the lowest values of performance indices while comparing with some recent algorithms. The same is also shown in Figure 4.

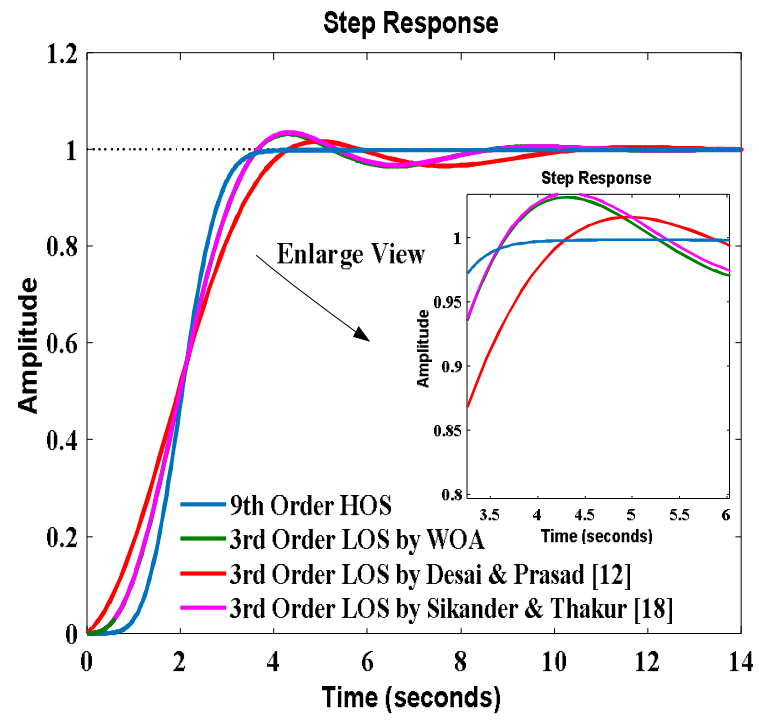

Figure 2: Step response of HOS and LOS for Example-1 


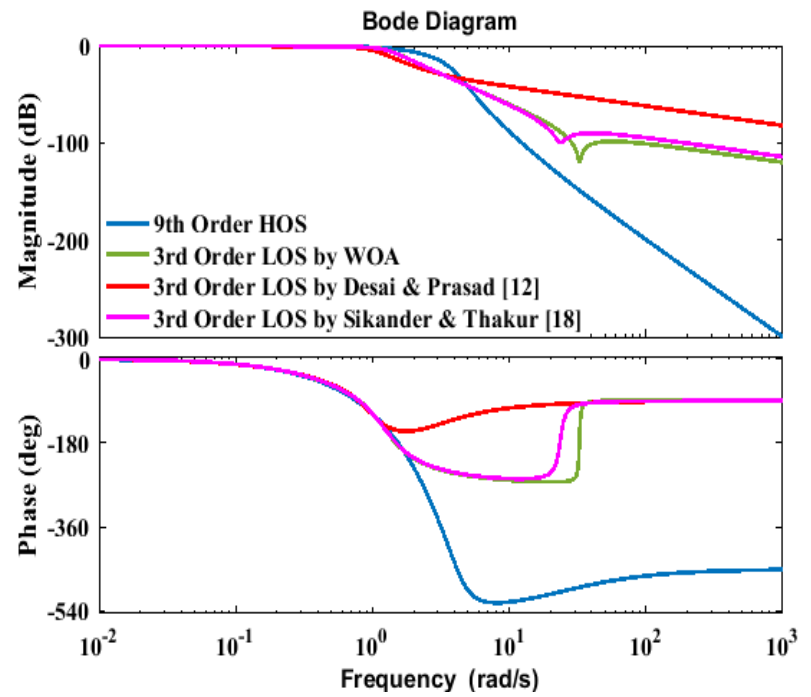

Figure 3: Bode plots of HOS and LOS for Example-1

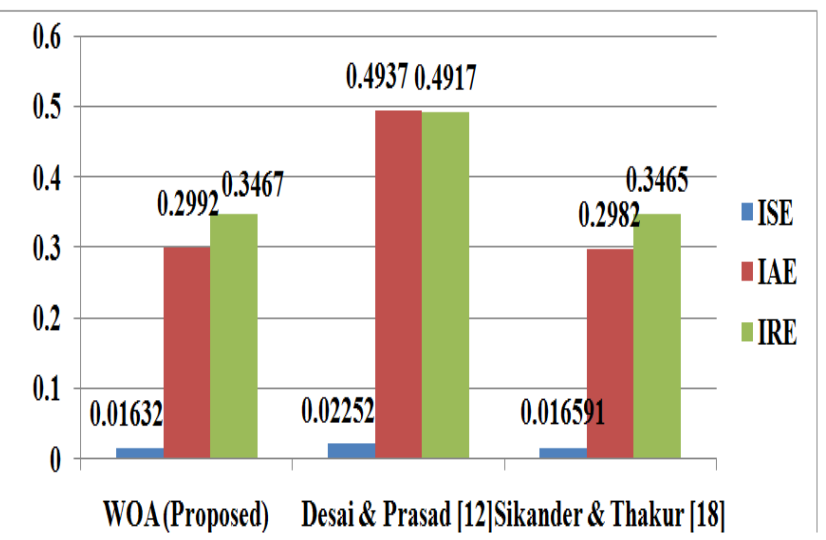

Figure4: Bar chart comparison for Example-1

Table 1(a):Comparison for the performance indices obtained by proposed WOA \& some recent algorithmsfor Example-1

\begin{tabular}{|c|c|c|c|}
\hline Literature & ISE & IAE & IRE \\
\hline Original Model & - & - & 0.4705 \\
\hline WOA (Proposed) & $\begin{array}{c}1.632 \mathrm{x} \\
10^{-2} \\
\end{array}$ & 0.2992 & 0.3467 \\
\hline $\begin{array}{c}\text { Desai \& Prasad } \\
{[12]}\end{array}$ & $\begin{array}{c}2.252 \mathrm{x} \\
10^{-2}\end{array}$ & 0.4937 & 0.4917 \\
\hline $\begin{array}{c}\text { Sikander\& Thakur } \\
{[18]}\end{array}$ & $\begin{array}{c}1.6591 \mathrm{x} \\
10^{-2}\end{array}$ & 0.2982 & 0.3465 \\
\hline $\begin{array}{c}\text { Mukherjee et al. } \\
{[24]}\end{array}$ & $\begin{array}{c}8.77 \mathrm{x} \\
10^{-2} \\
\end{array}$ & 0.9359 & 0.5085 \\
\hline $\begin{array}{c}\text { Vishwakarma\& } \\
\text { Prasad [25] }\end{array}$ & $\begin{array}{c}5.86 \mathrm{x} \\
10^{-2}\end{array}$ & 0.2060 & 0.6974 \\
\hline
\end{tabular}

Table 1 (b): Comparison for the transient response parameters obtained by proposed WOA \& some recent algorithms for

\begin{tabular}{|c|c|c|c|}
\hline \multicolumn{1}{c|}{$\begin{array}{c}\text { Performance } \\
\text { Parameters }\end{array}$} & $\begin{array}{c}\text { Rise } \\
\text { Time } \\
\text { (sec.) }\end{array}$ & $\begin{array}{c}\text { Settling } \\
\text { Time } \\
\text { (sec.) }\end{array}$ & $\begin{array}{c}\text { Over Shoot } \\
(\%)\end{array}$ \\
\hline $\begin{array}{c}\text { Original Model } \\
\text { WOA } \\
\text { (Proposed) }\end{array}$ & 1.52 & 3.28 & 0.346 \\
\hline $\begin{array}{c}\text { Desai \& Prasad } \\
\text { [12] }\end{array}$ & 2.77 & 9.08 & 3.16 \\
\hline $\begin{array}{c}\text { Sikander\& } \\
\text { Thakur [18] }\end{array}$ & 2.15 & 7.62 & 1.75 \\
\hline $\begin{array}{c}\text { Mukherjee et } \\
\text { al. [24] }\end{array}$ & 2.92 & 6.91 & 0 \\
\hline $\begin{array}{c}\text { Vishwakarma\& } \\
\text { Prasad [25] }\end{array}$ & 2.60 & 5.15 & 0 \\
\hline
\end{tabular}

\subsection{Example-2}

Let a $4^{\text {th }}$ order system with repeated polesbe defined as [18]:

$$
G_{4}(s)=\frac{1}{(s+1)^{4}}
$$

After WOA being applied, the following denominator and numerator's polynomials of LOS are obtained with ISE as $1.495 \times 10^{-2}$ :

$$
\begin{aligned}
& D_{2}(s)=9.9984 s^{2}+6.3484 s+1.6771 \\
& N_{2}(s)=0.001 s+1.6771
\end{aligned}
$$

Therefore, the $2^{\text {nd }}$ order LOS is:

$$
R_{2}(s)=\frac{0.001 s+1.6771}{9.9984 s^{2}+6.3484 s+1.6771}
$$

The convergence of ISE by WOA is shown in Figure 5

The comparison of responses, its parameters and performance indices obtained by the proposed WOA and some recent algorithms for $4^{\text {th }}$ order HOS and $2^{\text {nd }}$ order LOS have been shown in Figures6-7 and Tables 2(a)-2(b). The same observations (i) through (iii) as in Example- 1 have also been observed for the Example-2 which shows the superiority of WOA than other recent algorithms. Further, the performance of proposed algorithm is also shown in Figure 8. 


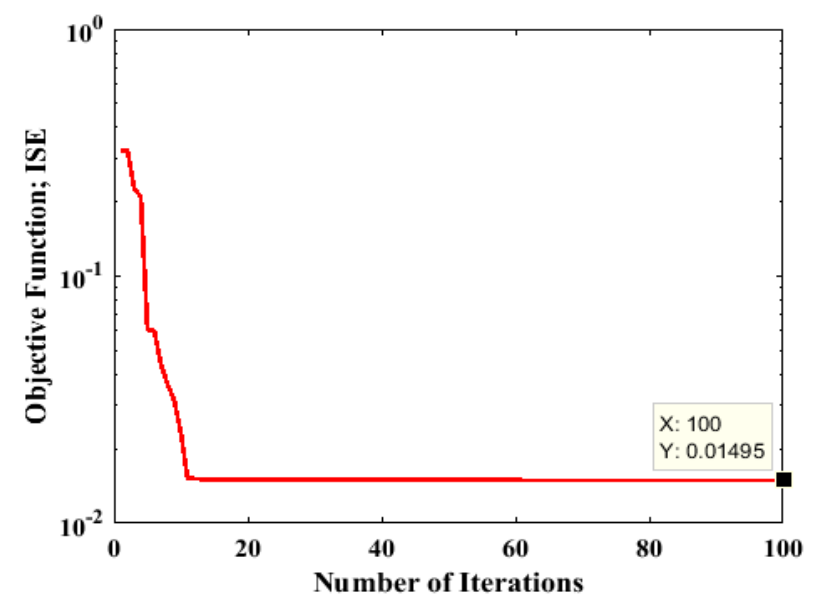

Figure 5: Convergence of objective function for Example-2

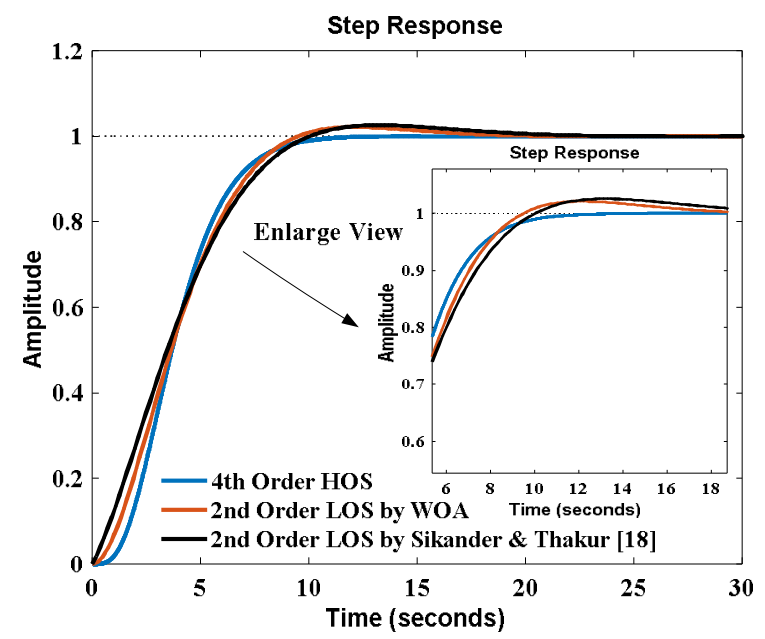

Figure 6:Step response of HOS and LOS for Example-2

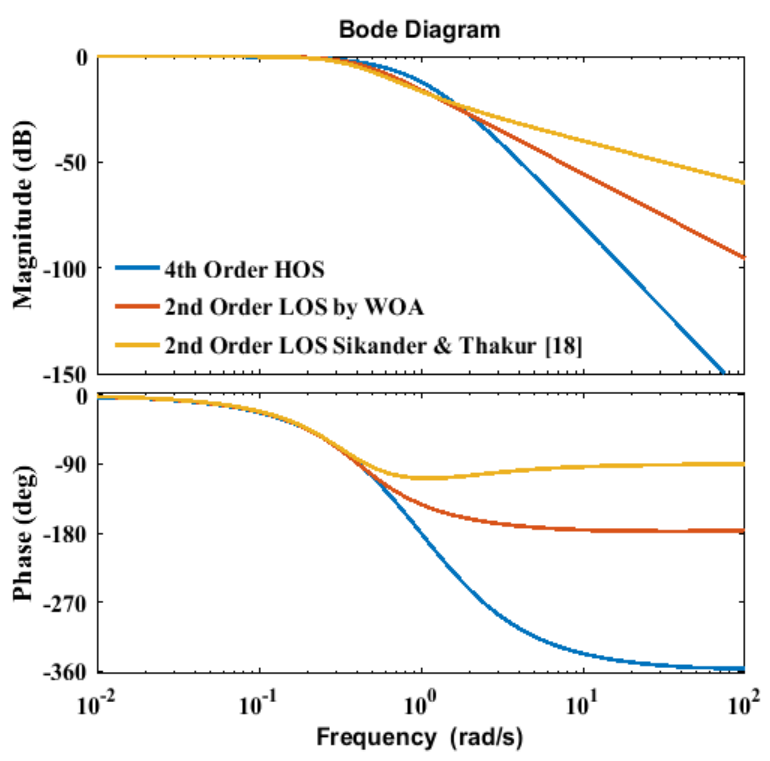

Figure 7:Bode plots of HOS and LOS for Example-2
Table 2 (a): Comparison for the performance indices obtained by proposed WOA \& some recent algorithms forExample-2

\begin{tabular}{|c|c|c|c|c|}
\hline $\begin{array}{c}\text { Performance } \\
\text { Parameters }\end{array}$ & $\begin{array}{c}\text { Reduced } \\
\text { Models }\end{array}$ & IRE & ISE & IAE \\
\hline $\begin{array}{c}\text { Original } \\
\text { Model }\end{array}$ & - & 0.1562 & - & - \\
\hline $\begin{array}{c}\text { WOA } \\
\text { (Proposed) }\end{array}$ & $\frac{0.001 s+1.6771}{9.9984 s^{2}+6.3484 s+1.6771}$ & 0.1319 & $\begin{array}{c}1.495 \\
\mathrm{X} 10^{-2}\end{array}$ & 0.4133 \\
\hline $\begin{array}{c}\text { Sikander\& } \\
\text { Thakur [18] }\end{array}$ & $\frac{0.1 s+0.1158}{s^{2}+0.5202 s+0.1158}$ & 0.1219 & $\begin{array}{c}4.58 \mathrm{x} \\
10^{-2}\end{array}$ & 0.6764 \\
\hline
\end{tabular}

Table 2 (b): Comparison for the transient response parameters obtained by proposed WOA \& some recent algorithms forExample-2

\begin{tabular}{|c|c|c|c|}
\hline $\begin{array}{c}\text { Performance } \\
\text { Parameters }\end{array}$ & $\begin{array}{c}\text { Rise Time } \\
\text { (sec.) }\end{array}$ & $\begin{array}{c}\text { Settling } \\
\text { Time (sec.) }\end{array}$ & $\begin{array}{c}\text { Over } \\
\text { Shoot (\%) }\end{array}$ \\
\hline $\begin{array}{c}\text { Original Model } \\
\text { WOA }\end{array}$ & 4.94 & 9.08 & 0 \\
\hline $\begin{array}{c}\text { (Proposed) } \\
\text { Sikander\& } \\
\text { Thakur [18] }\end{array}$ & 5.8 & 13 & 2.12 \\
\hline
\end{tabular}

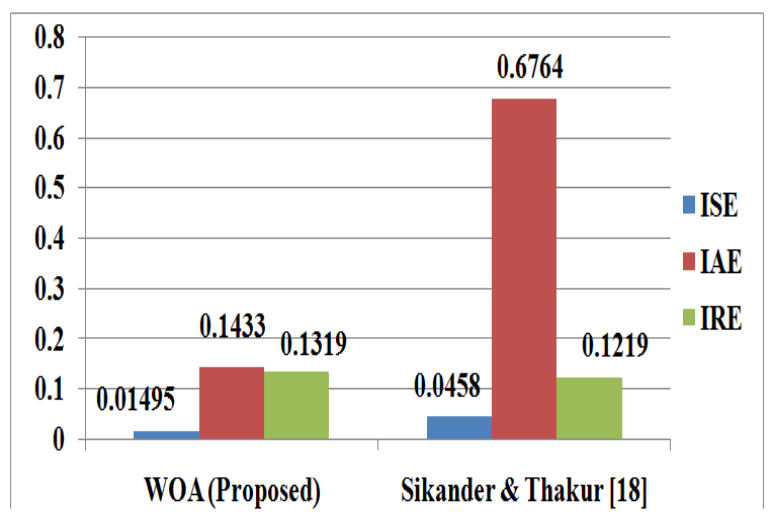

Figure 8: Bar chart comparison for Example-2

\subsection{Example-3}

Let a practical example of IEEE type 1 (DC) excitation model of $4^{\text {th }}$ order be given by [33]:

$$
G_{4}(s)=\frac{400 s+400}{0.0001 s^{4}+0.03 s^{3}+1.36 s^{2}+34.32 s+1.15}
$$


After WOA being applied, the following denominator and numerator's polynomials of LOS are obtainedwith ISE as $3.736 \times 10^{-1}$ (Convergence diagram in Figure 9):

$$
\begin{aligned}
& D_{2}(s)=s^{2}+21.4829 s+0.7196 \\
& N_{2}(s)=252.8464 s+250.2952
\end{aligned}
$$

Therefore, the $2^{\text {nd }}$ order LOS is:

$$
R_{2}(s)=\frac{252.8464 s+250.2952}{s^{2}+21.4829 s+0.7196}
$$

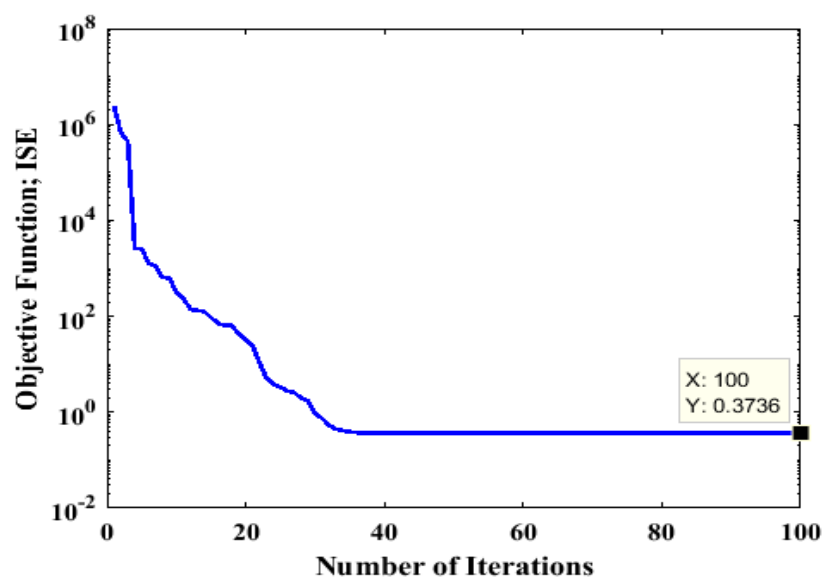

Figure 9: Convergence of ISE for Example-3

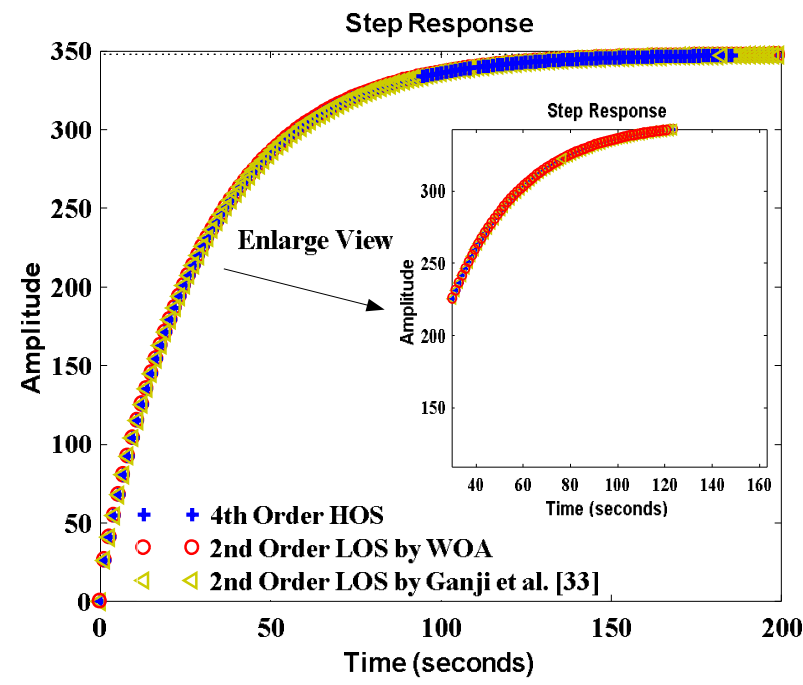

Figure 10: Step response of HOS and LOS for Example-3

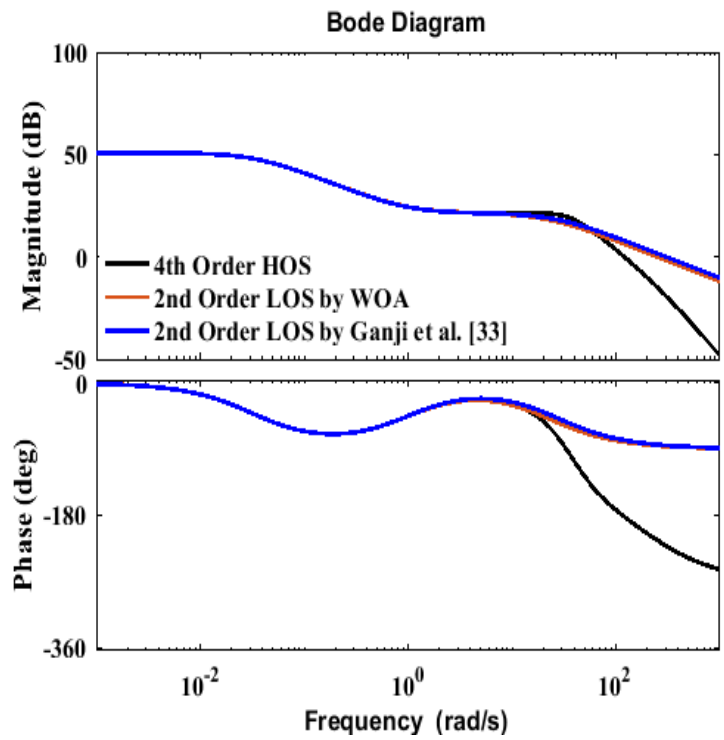

Figure 11:Bode plots of HOS and LOS for Example-3

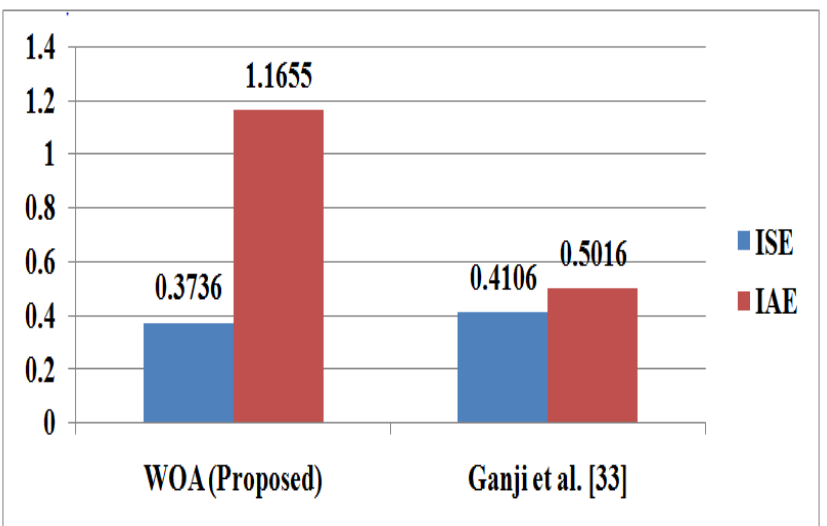

Figure 12:Bar chart comparison for Example-3

Table 3(a) : Comparison for the performance indices obtained by proposed WOA \& some recent algorithms forExample-3

\begin{tabular}{|c|c|c|c|c|}
\hline Literature & Reduced Models & IRE & ISE & IAE \\
\hline $\begin{array}{c}\text { Original } \\
\text { Model }\end{array}$ & - & 4028.7 & - & - \\
\hline $\begin{array}{c}\text { WOA } \\
\text { (Proposed) }\end{array}$ & $\frac{2528464 s+250.2952}{s^{2}+21.4829 s+0.7196}$ & 3799.26 & $\begin{array}{c}3.736 \\
\times 10^{-1}\end{array}$ & 1.1655 \\
\hline $\begin{array}{c}\text { Ganji et al. } \\
\text { [33] }\end{array}$ & $\frac{306.565826 s+306.681976}{s^{2}+26.312263 s+0.881711}$ & 4149.217 & $\begin{array}{c}4.106 \\
\times 10^{-1}\end{array}$ & 0.5016 \\
\hline
\end{tabular}


Table 3 (b): Comparison for the transient response parameters obtained by proposed WOA \& some recent algorithms forExample-3

\begin{tabular}{|c|c|c|c|}
\hline $\begin{array}{c}\text { Performance } \\
\text { Parameters }\end{array}$ & $\begin{array}{c}\text { Rise } \\
\text { Time } \\
\text { (sec.) }\end{array}$ & $\begin{array}{c}\text { Settling } \\
\text { Time } \\
\text { (sec.) }\end{array}$ & $\begin{array}{c}\text { Over } \\
\text { Shoot }(\%)\end{array}$ \\
\hline Original Model & 65.5 & 116 & $2.22 \mathrm{x}$ \\
$10^{-14}$
\end{tabular}

The comparison of responses, its parameters and performance indices obtained by the proposed WOA and some recent algorithms for HOS in Example-3 and $2^{\text {nd }}$ order LOS have been shown in Figures10-11 and Tables 3(a)-3(b). The same observations (i) through (iii) as in Examples-1and 2 have also been observed for the Example-3 which shows the superiority of WOA than other recent algorithms. Further, the performance of proposed algorithm is also shown in Figure 12.

\section{CONCLUSIONS}

In the present work, the stable reduced order models of LTIC systems have been obtained using WOA which evaluates the unknown parameters of numerator and denominator of LOS by minimizing ISE as an OF. Both time and frequency responses have been drawn and it has been found that the reduced order model provides a very close approximation to the original system. It has also been observed that WOA based LOS gives more accurate and stable performance than some recent algorithms available in the literature. Further, the effectiveness and superiority of the proposed algorithm have also been computed by both time response parameters and performance indices. A relative comparison among all parameters obtained by WOA and some recent algorithms have also been carried out which shows the better performance of reduced order model using WOA among aforesaid algorithms without losing all the essential characteristics.

\section{REFERENCES}

1. S. Ghosh and N. Senroy, "Balanced truncation approach to power system model order reduction", Electr. Power Compon. Syst. 41, 747-764 (2013)

2. R. Bhatt, G. Parmar and R. Gupta, "Application of WOA in reduced order modeling of LTI systems",

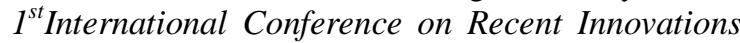
in Electrical, Electronics and Communication
Systems (RIEECS2017), Graphic Era University, Dehradun (U.K.), India.

3. G. Parmar, S. Mukherjee and R. Prasad, "System reduction using eigen spectrum analysis and pade approximation technique", International Journal of Computer Mathematics, Taylor \& Francis, 84, 1871-1880 (2007)

4. G. Parmar, S. Mukherjee and R. Prasad, "System reduction using factor division algorithm and eigen spectrum analysis", Applied Mathematical Modelling, 31, 2542-2552 (2007)

5. A. Nadi, O. Alsmadi and Z. Hammour, "Reduced order modeling of linear MIMO systems using particle swarm optimization", $7^{\text {th }}$ International Conference on Autonomic and Autonomous Systems (ICAS), Venice, Italy, 62-66 (2011)

6. S. Mirjalili and A. Lewis, "The whale optimization algorithm", Advance Engineering Software,95, 51-67 (2016)

7. J. Singh, K. Chatterjee and C. B. Vishwakarma, "System reduction by eigen permutation algorithm and improved padé approximations", IJMCPECE, World Academy of Science, Engineering and Technology, 8, 180-184 (2014)

8. C. B. Vishwakarma, "Model order reduction of linear dynamic systems for control system design", Ph. D. Thesis, IIT Roorkee, Roorkee India, (2009)

9. P. Saraswat, and G. Parmar, "A comparative study of differential evolution and simulation annealing for order reduction of large scale systems", IEEE Conf. on Communication, Control and Intelligent Systems (CCIS-2015), GLA Univ., Mathura (U.P.), India (2015)

10. L. S. Shieh and Y. J. Wei, "A mixed method for multivariable system reduction", IEEE Trans. Automat. Control, vol. AC-20, pp. 429-432, 1975.

11. A. Narwal and R. Prasad, "A novel order reduction approach for LTI systems using cuckoo search optimization and stability equation", IETE Journal of Research,62, 154-163 (2016)

12. S. R. Desai and R. Prasad, "A new approach to order reduction using stability equation and big bang big crunch optimization", Systems Science \& Control Engineering, 1, 20-27 (2013)

13. P. Boby and J. Pal, "An evolutionary computation-based approach for reduced order modeling of linear systems”, IEEE International Conference on Computational Intelligence and Computing Research, ICCIC, 28-29 (2010)

14. S. R. Desai and R. Prasad, "A novel order diminution of LTI systems using big bang big crunch optimization and routh approximation", Applied Mathematical Modelling, 37, 8016-8028 (2013) https://doi.org/10.1016/j.apm.2013.02.052

15. A. Nadi and O. Alsmadi, "Invasive weed optimization for model order reduction of linear MIMO systems", Applied Mathematical Modelling, 37, 4570-4577 (2013)

16. A. Sikander and R. Prasad, "Soft computing approach for model order reduction of linear time 
invariant system", Ckt. Systems \& Sig. Processing, Springer Science, New York, 34, 3471-3487 (2015)

17. A. Sikander and R. Prasad, "A new technique for reduced-order modelling of linear time-invariant system", IETE Journal of Research, 1-9, 2017.

18. A. Sikander and P. Thakur, "Reduced order modelling of linear time invariant system using modified cuckoo search algorithm", Soft Computing, Springer-Verlag Berlin Heidelberg, 1-11 (2017)

19. A. Sikander and R. Prasad, "A novel order reduction method using cuckoo search algorithm", IETE Journal of Research, 61, 83-90 (2015).

20. I. Khanam and G. Parmar, "Application of stochastic fractal search in order reduction of large scale LTI systems", IEEE International Conference on Computer, Communications and Electronics (Comptelix 2017), Manipal University, Jaipur,190-194 (2017)

21. D. K. Sambariya and O. Sharma, "Model order reduction using routh approximation and cuckoo search algorithm", Journal of Automation and Control, 4, 1-9 (2016)

22. D. K. Sambariya and G. Arvind, "High order diminution of LTI system using stability equation method", British Journal of Mathematics \& Computer Science, 13, 1-15 (2016)

23. D. K. Sambariya and H. Manohar, "Preservation of stability for reduced order model of large scale systems using differentiation method", British Journal of Mathematics \& Computer Science, 13, 1-17 (2016)

24. S. Mukherjee, R. Satakshi and C. Mittal, "Model order reduction using response matching technique", J. FranklInst, 342, 503-519 (2005)

25. C. B. Vishwakarma and R. Prasad, "MIMO system reduction using modified pole clustering and genetic algorithm", Model Simul Eng, 1-5 (2009)

26. S. Biradar, Y. V. Hote and S. Saxena, "Reduced-order modeling of linear time invariant systems using big bang big crunch optimization and time moment matching method", Applied Mathematical Modelling, 40, 7225-7244 (2016)

27. M. G. Safonoy and R. Y. Chiang, "Model reduction for robust control: a Schur relative error method", Int. J. Adapt. Control Signal, 2, 259-272 (1988)

28. D. K. Sambariya and O. Sharma, "Routh approximation : an approach of model order reduction in SISO and MIMO systems", Indonesian Journal of Electrical Engineering and Computer Science, 2, 486-500 (2016)

29. A. Sikander and R. Prasad, "New technique for system simplification using cuckoo search and ESA", Indian Academy of Sciences, 1-6 (2017)

30. S. Mukherjee, M. Satakshi, and R. C. Mittal, "Model order reduction using response matching technique", J. Franklin Inst., 342, 503-519 (2005)

31. A. K. Mittal, R. Prasad. and S. P. Sharma, "Reduction of linear dynamic systems using an error minimization technique", Journal of Institution of
Engineers, India, IE(I) Journal - EL, 84, 201-206 (2004)

32. S. Panda, J. S. Yadav, N. P. Patidar and C. Ardil, "Evolutionary techniques for model order reduction of large scale linear systems", International Journal of Electrical, Computer, Energetic, Electronic and Communication Engineering, 6 (2012)

33. V. Ganji, S. Mangipudi and R. Manyala, "A novel model order reduction technique for linear continuos-time systems using PSO-DV algorithm", J Control AutomElectrSyst, (2016).

34. V. Soni, G. Parmar and M. Kumar. A hybrid grey wolf optimization and pattern search algorithm for automatic generation control of multi area interconnected power systems, International Journal of Advanced Intelligence Paradigms (IJAIP), Inderscience, In Press (Scopus Indexed) (2018).

35. V. Soni, G. Parmar, M. Kumar and S. Panda, "Hybrid grey wolf optimization-pattern search ( $h$ GWO-PS) optimized 2DOF-PID controllers for load frequency control (LFC) in interconnected thermal power plants", ICTACT Journal on Soft Computing, Vol. 6, No. 3, pp. 1244-1256 (2016).

36. V. Soni, G. Parmar, M. Kumar and S. Panda, "Application of $h$ GWO-PS to three area interconnected hyro-thermal power system for AGC", Ciencia E Technica, A Science and Technology Journal, An SCI Expanded Journal, Vol. 31, No. 7, pp. 50-65 (2016).

37. V. Soni, G. Parmar, M. Kumar and S. Panda, " $h$ GWO-PS optimized 2DOF-PID controller for non reheat two areas interconnected thermal power plants: a comparative study”, 2016 IEEE conference on Power Electronics, Intelligent Control and Energy Systems (ICPEICES-2016), Delhi Technological University, Delhi, India, pp. 1-6, July 4-6 (2016).

38. K. Kumar, G. Kumar and J. Singh. An effective combination technique for artificial intelligence based ensembles for intrusion detection. International Journal of Advanced Trends in Computer Science and Engineering (IJATCSE), Vol.2, No.5, pp. 29-36 (2013).

39. V. Enireddy, K. Gunda, N. L. Kalyani, K.B. Prakash. Nature inspired binary grey wolf optimizer for feature selection in the detection of neuro degenerative (Parkinson) Disease. International Journal of Advanced Trends in Computer Science and Engineering (IJATCSE), Vol. 9, No.3 (2020). https://doi.org/10.30534/ijatcse/2020/222932020

40. B. J. Chelliah, K. Shreya, A. Raha, M. Sravya.An optimized and unique methodology for software test case automation strategy. International Journal of Advanced Trends in Computer Science and Engineering (IJATCSE), Vol. 9, No.2 (2020). https://doi.org/10.30534/ijatcse/2020/183922020 